\title{
A SIMULATION MODEL FOR STUDYING THE EFFECT OF STAND STRUCTURE ON HARVESTING PATTERN
}

\author{
By R. M. NEWNHAM ${ }^{1}$
}

\section{$R E ́ S U M E$}

Le présent article décrit un modèle simulateur simple qui imite le passage d'une abatteuse mécanique, telle qu'une abatteuse Beloit ou Hiabob, à travers un peuplement de bois à pâte. En utilisant ce modèle commandé par un programme passant dans un ordinateur I.B.M. 1620, il est possible d'étudier l'effet de la structure du peuplement et de la grosseur de la machine sur l'organisation du travail de coupe. L'auteur propose certaines modifications à apporter au modèle pour tenir compte de l'estimation du temps de manoeuvre. Dans sa forme définitive, le modèle pourra fournir des renseignements qui seront utiles pour la conception technique de la machine, ainsi que pour son utilisation en exploitation forestière.

\section{ABSTRACT}

A simple simulation model is described which imitates the passage of a mechanical harvester, such as the Beloit or Hiabob harvesters, through a pulpwood stand. Using this model, which has been programmed for an I.B.M. 1620 computer, it is possible to study the effect that stand structure and machine size have on harvesting pattern. Modifications to the model to include estimates of operating time are suggested. In its final form the model could furnish information that will be of much use to the machine designer and to the woodland manager.

\section{INTRODUCTION}

In recent years increasing attention has been paid in eastern Canada to the tree-length logging concept whereby trees are limbed, topped, felled and sometimes sawn into pulpwood lengths by one machine. Such machines are expensive so it is essential that they be designed for the most efficient operation possible over a wide range of stand conditions. Although fully mechanized logging accomplishes a considerable reduction in harvesting costs, we should still strive for the most efficient harvesting method.

A simulation model is a mathematical model which imitates a real life process. This paper will describe a simple simulation model which enables us to study machine harvesting patterns without recourse to expensive field trials. It will not deal with the possible harmful effects of full tree logging on site degradation and the subsequent difficulty in re-establishing the stand as these have been discussed elsewhere (Silversides, 1964; Smither, 1964; Weetman, 1965). Cost reductions due to logging mechanization must be sufficiently great to offset any increase in regeneration costs caused by the new methods (Smithers, 1964).

'Research Scientist, Forest Management Research and Services Institute, Department of Forestry of Canada, Ottawa. 
Tree stems may occur uniformly, or regularly, distributed over the whole area of the stand, as in plantations where the trees occur at fixed intervals, or they may be randomly distributed over the area as in some natural stands. In some stands the trees tend to occur in clumps due to irregular seed source, site irregularities, disease or insect damage. In most even-aged stands, the trees tend to become more uniformly distributed with age, at least to the point where the stand starts to degenerae. Some of the methods of determining spatial patterns and distributions have been described by Greig-Smith (1957), Pielou (1959) and Foster and Johnson (1963). The characteristics of a randomly distributed population have been evaluated by Cottam et al. (1953). Sampling methods to show whether a population departs from randomness have been described by Clark and Evans (1954), Cottam and Curtis (1956) and Thompson (1956). Although these tests will show whether the trees in a stand tend to occur in clumps, they do not show what form the clumps take or their size and distribution. This can be done by the contiguous quadrat method of Greig-Smith (1952) of by the more recent method of Pielou (1964). A method that will describe the spatial pattern of forest stands on a trees-per-clump basis rather than on a treesper-quadrat basis is currently being prepared. The main problem is in choosing an objective method of delineating the clumps.

\section{METHOD}

In the present investigation two artificially created populations were used for testing the model. One had a random distribution (Figure 1) and the other a clumped distribution of trees (Figure 2). The method of generating these distributions has been described previously ${ }^{2}$. The harvesting machines tested were of the Beloit-Hiabob type which move from point to point, harvesting all the trees from each point which come within reach of its swinging boom.

In practice the machine would not have to cover the whole area of the stand by making constant advances approximately equal to the boom length, but would advance until it was necessary to stop, i.e. to proceed further would mean missing a tree. Thus the average point-to-point distance would be greater than the fixed, point-to-point distance required to cover the whole area. An example of the pattern of harvesting for a 29.5 foot boom is shown in Figure 1.

The model has been used to determine the distributions of point-topoint distances, point-to-tree distances and number of trees harvested per point. The "point-to-tree" distance is the distance the boom has to be extended from the machine to harvest a tree. The form that these distributions take depends on the length of the boom (radius of sweep) and the spatial distribution of trees in the stand. The model has been used to test boom lengths of 14.75, 22, and 29.5 feet in the two populations shown in Figures 1 and 2 . It was assumed that:

\footnotetext{
- Newnham, R. M. 1965. The effect of the spatial distribution of trees on the design of harvesting machinery. Dept. of Forestry of Canada, 65-H-5, Unpubl. Rep.
} 


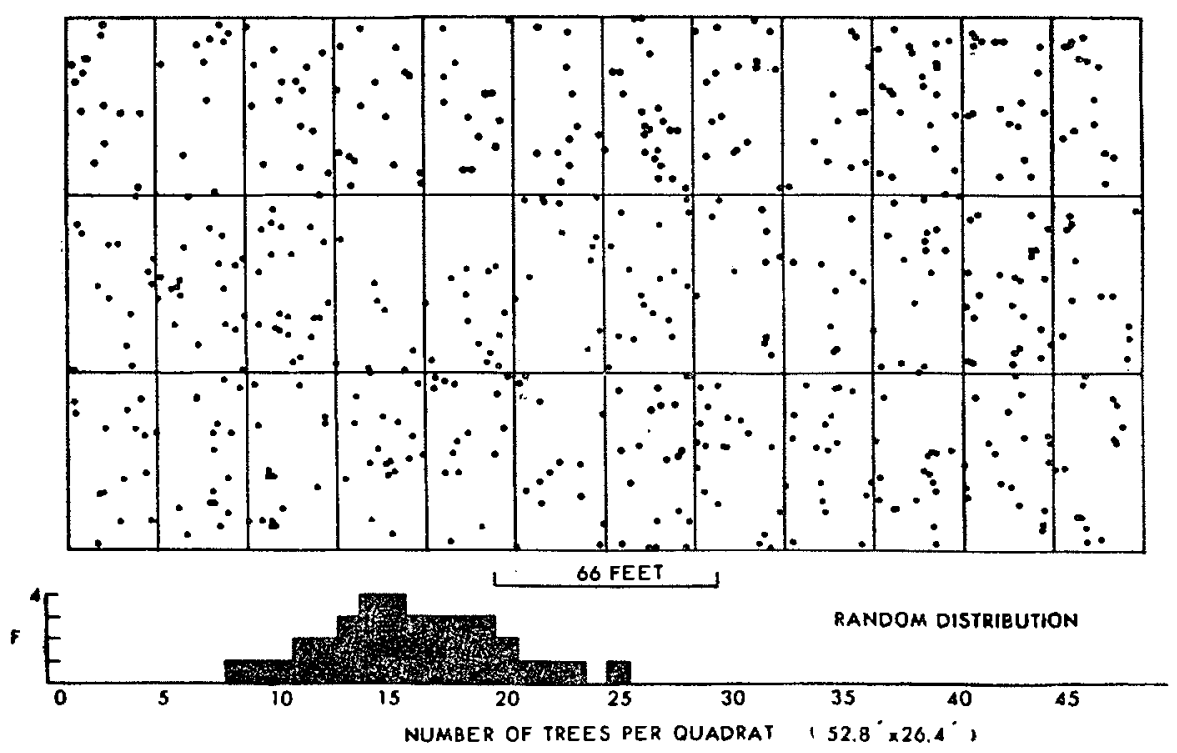

FIGURE 1. The random distribution of trees used for testing the model.

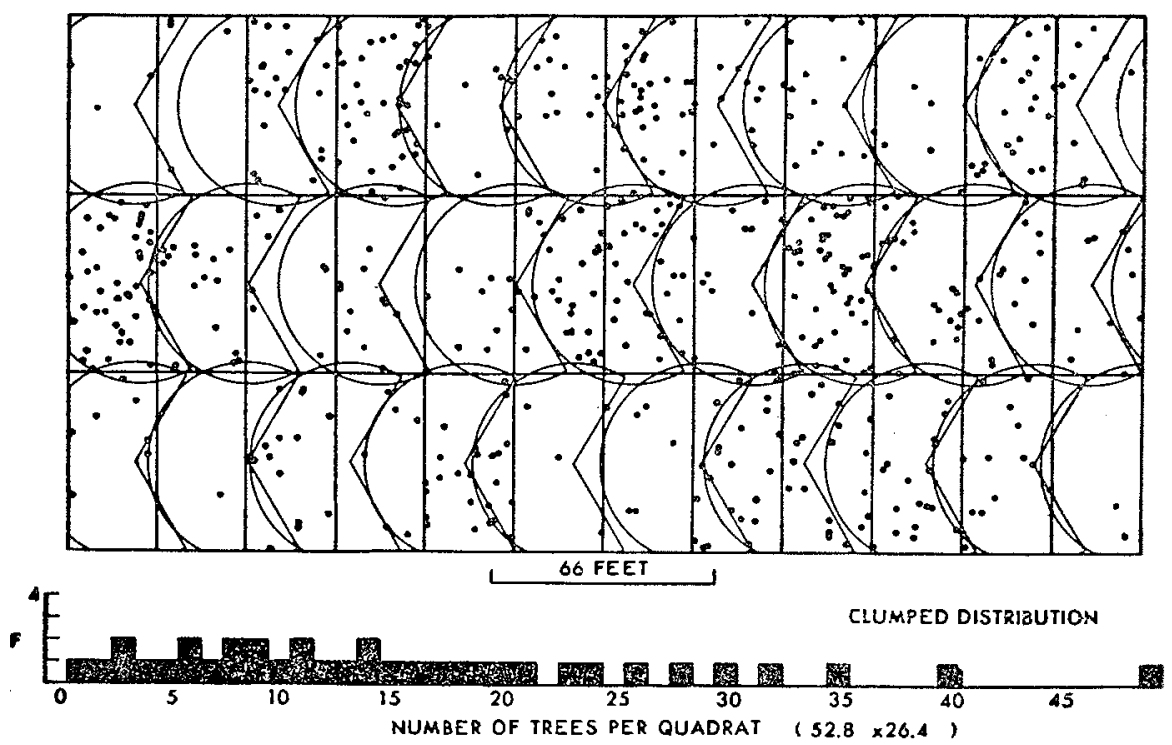

FIGURE 2. The clumped distribution of trees used for testing the model. The pattern of harvesting shown is that for a machine with a radius of sweep of 29.5 feet. 
(a) the harvester moved along the centres of straight parallel strips whose widths were equal to $1.79 \mathrm{R}$ where $\mathrm{R}$ is the boom length (radius of sweep);

(b) the strips were continuous, the last tree in strip 1 being the first in strip 2 (i.e. there was no turn round time);

(c) trees could not be harvested outside the boundaries of each strip (errors involved in making this assumption tend to cancel each other out), nor could they be harvested while the machine was moving between points;

(d) the swing of the boom was restricted to an arc of 240 degrees.

Among the factors affecting the design of the harvesting machine are topography, micro-topography (the degree of unevenness of the ground), soil structure, the size and distribution of the tree stems and the species composition. The simulation model that is described here has been used to evaluate the effect of stand structure (the spatial distributionn of the trees in a stand) on machine harvesting patterns. The model has been programmed for an I.B.M. 1620 computer which can "harvest" a stand having a density of 500 trees per acre at the rate of 8 minutes per acre.

\section{Results (Table 1)}

The model is still in the early stages of development. The results shown in Table 1 demonstrate how the model can be used and also give some indication of the effect that stand structure and radius of sweep (boom length) have on harvesting pattern. Before definite conclusions could be reached, the model would have to be re-run several times using different starting points in the stand and different population samples. The following tentative conclusions can be drawn from these preliminary results.

\section{RAdIUS OF SWEEP (R)}

As would be expected the effect of increasing $R$ was to decrease the number of points or sweeps that were required to harvest the area. Increasing $R$ also increased the average point-to-point distance, the average number of trees harvested per sweep, and the average point-to-tree distance. The area of the stand actually covered by the machine's sweeps during harvesting operations was 64 to 67 per cent of the total area for $R=14.75$ feet but was much higher for the 22 and 29.5 foot radii ( 78 per cent). It would appear from these results that the shortest boom length was the most efficient. However, although covering a smaller area, the machine with the small boom had to travel a total distance of approximately 1,900 feet through the stand as against a total distance of 950 feet for the machine with the longest boom.

\section{Distribution OF TREES}

The distribution of the trees (spatial pattern) before harvesting had very little effect on the mean point-to-point distance, the mean number of trees harvested per sweep or the mean point-to-tree distance. There was some evidence for $\mathbf{R}=14.75$ feet that it may be necessary to make more sweeps to harvest a stand where the trees are randomly distributed than to harvest 
TABLE 1

The Effect of Stand Structure On Pornt-to-Point Distance, Number of Trees Harvested Per Sweep And Point-to-Tree Distance

\begin{tabular}{|c|c|c|c|c|c|c|}
\hline \multirow[t]{3}{*}{ Distribution of trees } & \multicolumn{3}{|c|}{ Clumped } & \multicolumn{3}{|c|}{ Random } \\
\hline & \multicolumn{3}{|c|}{$\begin{array}{c}\text { Radius of Swcep (R) } \\
\text { (feet) }\end{array}$} & \multicolumn{3}{|c|}{$\begin{array}{c}\text { Radius of Sweep (R) } \\
\text { (feet) }\end{array}$} \\
\hline & 14.75 & 22 & 29.5 & 14.75 & 22 & 29.5 \\
\hline $\begin{array}{l}\text { Total No. of sweeps } \\
\text { (points) }\end{array}$ & 93 & 49 & 28 & 97 & 49 & 28 \\
\hline $\begin{array}{l}\text { Mean point-to-point } \\
\text { distance (feet) }\end{array}$ & 20.4 & 25.9 & 33.9 & 19.6 & 25.9 & 33.9 \\
\hline Standard deviation & \pm 5.7 & \pm 4.8 & \pm 4.3 & \pm 3.9 & \pm 2.1 & \pm 2.7 \\
\hline $\begin{array}{l}\text { Mean No. of trees } \\
\text { per sweep }\end{array}$ & 6.1 & 11.6 & 20.3 & 5.9 & 11.6 & 20.3 \\
\hline Standard deviation & \pm 3.6 & \pm 6.6 & \pm 11.4 & \pm 2.3 & \pm 3.4 & \pm 4.5 \\
\hline $\begin{array}{l}\text { Mean point-to-tree } \\
\text { distance (feet) }\end{array}$ & 9.4 & 14.1 & 18.8 & 9.4 & 13.9 & 19.1 \\
\hline Standard deviation & \pm 4.0 & \pm 5.5 & \pm 7.3 & \pm 3.7 & \pm 5.4 & \pm 7.4 \\
\hline
\end{tabular}

a stand having the same number of trees per acre but where the trees are clumped. In stands where the trees are regularly distributed (e.g. plantations) the number of sweeps required might be even greater.

Although the averages were affected only a little by the spatial pattern of the trees, there were large differences between the standard deviations of the mean point-to-point distances and of the mean numbers of trees harvested per sweep for the two distributions. As might be expected these standard deviations were much greater in the clumped distribution. This illustrates the inadvisability of using unqualified means to describe a distribution. A large standard deviation indicates a large range as has been confirmed previously ${ }^{3}$. This increase in the range of values has to be considered in the selection of a suitable boom length, for if the number of trees harvested in a sweep becomes very large, the harvester may have difficulty in "bunching" the felled stems and the skidder difficulty in handling the large "bunches".

\section{Future Development}

The model described is very simple but could be developed to include the species and size of each tree. Modifications could also be made for machines having a minimum as well as a maximum working radius or having a working arc other than 240 degrees.

Estimates of time taken to harvest stands of different species composition and spatial pattern would also be possible if sufficient detailed information

Ibid. 
was available on the time taken to perform the different operations during harvesting. Once the total harvesting time has been estimated it is then possible to estimate the cost of logging using the different machines and thus to select the most economical.

The model might also be used for testing operator efficiency. The harvesting pattern of a machine in a mapped stand could be compared with the pattern produced by the computer. Does the operator make use of the full length of the boom? Does he move the machine too often? Is it more efficient to make large advances in narrow strips or small advances in relatively wide strips? Using the model much information about such questions could be obtained quickly and at a relatively low cost.

These are some of the problems for which the model can be used to provide answers. However, before carrying out further or more extensive tests, it is essential that we know what information will be of most use to the companies operating these machines and how the information will be used. There is no point in developing a highly sophisticated model unless it is going to have some practical application. Future work on this project will be carried out in close co-operation with the "men on the job."

\section{REFERENCES}

CLARK, P. J., and F. C. EVANS. 1954. Distance to nearest neighbour as a mensure of spatial relations in populations. Ecology, 35, 445-53.

COTTAM, G., and J. T. Curtis. 1956. The use of distance measures in phyto-sociological sampling. Ecology, 37, 451-60.

COTTAM, G., J. T. CURTIS and B. W. HALE. 1953. Some sampling characteristics of a population of randomly dispersed individuals. Ecology, 34, 741-57.

FOSTER, R. E., and A. L. S. JOHNSON. 1963. Assessment of pattern, frequency distribution, and sampling of forest disease in Douglas fir plantations. Dept. of Forestry of Canada, Publication 1011.

GREIG-SMITH, P. 1952. The use of random and contiguous quadrats in the study of the structure of plant communities. Ann. Bot. N.S., 16, 293-316.

1957. Quantitative plant ecology. Butterworth's Scientific Publications, London.

PIELOU, E. C. 1959. The use of point-to-plant distances in the study of the pattern of plant populations. J.Ecol., 47, 607-13. 20, 156-67.

1964. The spatial pattern of two-phase patchworks of vegetation. Biometrica,

SILVERSIDES, C. R. 1964. Developments in logging mechanization in eastern Canada. Univ. B.C., Fac. For., H. R. MacMillan lecture.

SMITHERS, L. A. 1964. The impact of mechanical logging on silviculture in Canada. Dept. of Forestry of Canada, Forest Research Branch Contribution 648.

THOMPSON, H. R. 1956. Distribution of distance to Nth neighbour in a population of randomly distributed individuals. Ecology, 37, 391-4.

WEETMAN, G. F. 1965. The need to study silviculture effects of mechanized logging aysreme in eastern Canada. For. Chron., 41, 252-6. 